\title{
Stanniocalcin 2 contributes to aggressiveness and is a prognostic marker for oral squamous cell carcinoma
}

Andreia Ferreira do Carmo ${ }^{a, b}$, Mauricio Rocha Dourado ${ }^{a}$, Carine Ervolino de Oliveira ${ }^{c}$, Débora Campanella Bastos ${ }^{a}$, Catherine Bueno Dominguetic, Lívia Máris Ribeiro Paranaíba $^{c}$, Íris Sawazaki-Calone ${ }^{\mathrm{d}}$, Gabriel Álvares Borges ${ }^{\mathrm{e}}$, Eliete Neves Silva Guerra ${ }^{\mathrm{e}}$, Renato C. Casarin ${ }^{f}$ Edgard Granera ${ }^{a}$ Tuula A. Salog, Roseana de Almeida Freitas ${ }^{b}$, Hébel Cavalcanti Galvãob ${ }^{\mathrm{b}}$ Ricardo D. Colettaa,

aDepartment of Oral Diagnosis, School of Dentistry, University of Campinas, PiracicabaSP, Brazil.

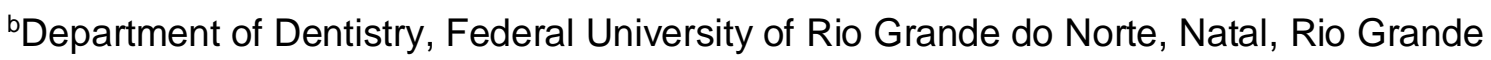
do Norte, Brazil.

'Department of Pathology and Parasitology, Institute of Biomedical Sciences, Federal University of Alfenas (UNIFAL-MG), Alfenas, Minas Gerais.

'Oral Pathology and Oral Medicine, Dentistry School, Western Paraná State University, Cascavel, Paraná, Brazil.

eLaboratory of Oral Histopathology, Health Sciences Faculty, University of Brasilia, Brasilia, Brazil.

fDepartment of Prosthodontics and Periodontics, School of Dentistry, University of Campinas, Piracicaba-SP, Brazil.

${ }^{9}$ Cancer and Translational Medicine Research Unit, Faculty of Medicine and Medical Research Center Oulu, Oulu University Hospital, University of Oulu, Oulu, Finland; Institute of Oral and Maxillofacial Disease, University of Helsinki, and HUSLAB, Department of Pathology, Helsinki University Hospital, Helsinki, Finland.

Running title: Stanniocalcin 2 in oral cancer. 
${ }^{*}$ Corresponding author: Ricardo D. Coletta, Department of Oral Diagnosis, School of Dentistry, University of Campinas, 13414-018 Piracicaba, São Paulo, Brazil, Email: coletta@fop.unicamp.br 


\section{ABSTRACT}

Stanniocalcin 2 (STC2), a glycoprotein that regulates calcium and phosphate homeostasis during mineral metabolism, appears to display multiple roles in tumorigenesis and cancer progression. This study aimed to access the prognostic value of STC2 in oral squamous cell carcinoma (OSCC) and its implications in oral tumorigenesis. STC2 expression was examined in 2 independent cohorts of OSCC tissues by immunohistochemistry. A loss-of-function strategy using shRNA targeting STC2 was employed to investigate STC2 in vitro effects on proliferation, apoptosis, migration, invasion, epithelial-mesenchymal transition (EMT) and possible activation of signaling pathways. Moreover, STC2 effects were assessed in vivo in a xenograft mouse cancer model. High expression of STC2 was significantly associated with poor diseasespecific survival (HR: 2.67, 95\% Cl: $1.37-5.21, \mathrm{p}=0.001)$ and high rate of recurrence with a hazard ratio of $2.80(95 \% \mathrm{Cl}: 1.07-5.71, \mathrm{p}=0.03)$. In vitro downregulation of STC2 expression in OSCC cells attenuated proliferation, migration and invasiveness while increased apoptotic rates. In addition, the STC2 downregulation controlled EMT phenotype of OSCC cells, with regulation on E-cadherin, vimentin, Snail1, Twist and Zeb2. The reactivation of STC2 was observed in the STC2 knockdown cells in the in vivo xenograft model, and no influence on tumor growth was observed. Modulation of STC2 expression levels did not alter consistently the phosphorylation status of CREB, ERK, JNK, p38, p70 S6K, STAT3, STAT5A/B and AKT. Our findings suggest that STC2 overexpression is an independent marker of OSCC outcome and may contribute to tumor progression via regulation of proliferation, survival and invasiveness of OSCC cells.

Keywords: Stanniocalcin 2; oral cancer; prognosis; tumor progression. 


\section{Introduction}

Oral squamous cell carcinoma (OSCC), the most common tumor in the head and neck region, displays high incidence (more than 350,000 new cases every year) and rates of mortality (approximately 177,000 deaths every year) [1]. Since OSCCs are asymptomatic at early stages, most patients are diagnosed at advanced stage of disease, resulting in a 5-year survival rate of approximately $50 \%$ [2]. Tumor invasion, lymph node metastasis and high rates of locoregional recurrence are the main factors leading to the death of patients with OSCC [3]. Therefore, biomarkers of early diagnosis, prognosis and post-therapeutic monitoring are essential to improve clinical management of OSCC. Indeed, several studies have reported potential biomarkers for predicting OSCC progression and prognosis, however, their practical usefulness remains very limited [4].

Stanniocalcins are glycoprotein hormones involved in calcium and phosphate homeostasis [5]. Two isoforms are known in mammalians, stanniocalcin 1 and stanniocalcin 2 (STC2), which are encoded by distinct genes [6]. Besides the canonical function in calcium/phosphate regulation, promoting inorganic phosphate-induced mineralization and preventing ectopic calcification, STC2 has been related to proliferation, apoptosis, invasion and epithelial-mesenchymal transition (EMT) when upregulated in tumors [7-9]. A recent systematic review and meta-analysis revealed that high STC2 levels are frequently associated with advanced disease stage, lymph node metastasis and vascular invasion, factors that suggest worse prognosis, and most important, the high expression of STC2 significantly predicted poor overall survival [10]. However, in both female and male breast cancers, STC2 expression is a favorable prognostic factor, extending disease-free and overall survival [11-13]. In head and neck squamous cell carcinomas (HNSCC), STC2 expression level was associated with aggressiveness, and in vitro studies confirmed its role regulating apoptosis, proliferation, migration and invasion of HNSCC cells [14]. Upregulation of miR-206 on HNSCC suppressed STC2 biological effects via PI3K-AKT signaling pathway [15]. Although the 
emerging literature suggests the clinical importance of STC2 in human cancers as potential prognostic marker or therapeutic target, there are still very little molecular details defining the mechanisms of action of those proteins in the control of oral tumorigenesis.

In the current study we examined the expression levels of STC2 in OSCC clinical samples to determine the prognostic impact of this protein for OSCC patients. Moreover, we assessed whether STC2 knockdown influences OSCC cell proliferation, apoptosis, migration, invasion and EMT in vitro and growth of xenograft tumors in vivo. The STC2 effects on the main signaling pathways, which is known to promote oral tumorigenesis, were verified using the Luminex technology.

\section{Materials and Methods}

STC2 mRNA levels in previously published microarrays. To examine the expression pattern of STC2 in published microarray data, we performed a meta-analysis using data mining from the Oncomine ${ }^{\circledR}$ Research Premium Edition database (https://www.oncomine.org). The first step was to identify previously published microarray gene expression data comparing normal oral mucosa and OSCC. Filters for selection of the data were studies that included STC2 in the analysis, comparing cancer vs normal tissue, cancer type (squamous cell carcinoma) and primary tumor sites in the oral cavity. After applying those filters, a total of 9 datasets (312 samples) from published studies remained. The expression level was considered the median rank for the gene across each of the analysis, and the given $p$-value was based in the median-ranked analysis at a cut off $0.01(\mathrm{p}<0.01)$.

Tissue samples and clinicopathological data. This study included 2 independent cohorts of OSCC. The cohort 1 included 100 primary OSCCs diagnosed and treated by radical surgery at 2 reference hospitals (UOPECCAN and CEONC Cancer Hospitals) in Cascavel-Parana, between 1998 and 2008. The clinicopathological 
features of these patients were described previously [16]. The cohort 2 included 119 patients with OSCC treated at the Hospital Bom Pastor in Varginha-Minas Gerais, between 1998 and 2014. In this cohort, a male prevalence was observed ( $n=86,72.3 \%$ ) and the average age was $60.4 \pm 11.4$ years (range $21-87$ years). Smoking was reported by $84(70.6 \%)$ patients and alcohol consumption by 57 (47.9\%). Tumors were localized in the tongue ( $n=95,79.8 \%)$ or floor of mouth $(n=24,20.2 \%)$. Regarding clinical stage, 15 patients were stage I (12.6\%), 32 were stage II (26.9\%), 27 were stage III (22.7\%) and 45 were stage IV (37.8\%). Surgery as monotherapy was performed in 17 (14.3\%) patients, whereas 50 (42\%) were treated by a combination of surgery and postoperative radiotherapy and $52(43.7)$ by a combination of surgery and postoperative radiotherapy and chemotherapy. A total of $21(17.6 \%)$ tumors were classified as well-differentiated, $87(73.1 \%)$ as moderately-differentiated and $11(9.2 \%)$ as poorly-differentiated, according to the WHO grading system. During follow up, 24 (20.2\%) patients developed recurrence (17 local, 5 regional and 2 distant). The overall survival ranged between 8 to 116 months, with a mean of 84 months. Twenty patients (17.1\%) died due to the tumor. The study was approved by the ethics review board of each of the hospitals affiliated with the collaborative study, and revised by the Human Research Ethics Committee of the School of Dentistry, University of Campinas (protocol number: 090/2011).

Immunohistochemistry. Three- $\mu \mathrm{m}$ tissue sections were deparaffinized and hydrated using a graded series of ethanol until water. Sections were then subjected to antigen retrieval with $0.01 \mathrm{M}$ citrate buffer $\mathrm{pH} 6.0$ in an electric pressure cooker and incubation with $3 \%$ aqueous hydrogen peroxide for $15 \mathrm{~min}$ to quench endogenous peroxidase. Two anti-STC2 antibodies were used : anti-STC2 monoclonal antibody (Abcam, USA) diluted 1:50 (for the first cohort) and anti-STC2 polyclonal antibody (Thermofisher, USA) diluted 1:100 (for the second cohort). After primary antibody, slides were incubated with EnVision reagents (EnVision® + Dual Link System-HRP kit, Dako, USA) and developed with $0.6 \mathrm{mg} / \mathrm{ml} \mathrm{3,3'-diaminobenzidine} \mathrm{tetrahydrochloride} \mathrm{(Dako,}$ 
USA) and Mayer's hematoxylin as counterstained. The control reactions were performed by the exclusion of the primary antibody.

Immunoexpression of STC2 was semiquantitatively assessed taking in consideration the number of positive cells and the intensity of staining. The number of positive cells was graded in quartiles $(0,1: 1 \%-25 \%$ staining, $2: 26 \%-50 \%$ staining, 3 : $51 \%-75 \%$ staining, and $4: 76 \%-100 \%$ staining), and the intensity of staining was scored in 0: negative, 1: weak staining, 2: moderate staining and 3: strong staining. The 2 grades were added together, resulting in scores that ranged from 0 to 7 , and were classified as low (0-4 score) and high (5-7 score) expression for comparative analysis.

Cell culture. The immortalized normal human gingival keratinocyte cell line (HGK) was cultured in serum-free, low calcium media (Gibco's Keratinocyte-SFM; Invitrogen, USA) containing bovine pituitary extract, epidermal growth factor and antibiotics. Human OSCC cells SCC-4, SCC-9, SCC-15 and SCC-25 were purchased from the American Type Culture Collection (ATCC, USA) and cultured as recommended in a 1:1 mixture of Dulbecco's modified Eagle's media and Ham's F12 media (DMEM/F12; Invitrogen, USA) supplemented with $10 \%$ fetal bovine serum (FBS), $400 \mathrm{ng} / \mathrm{ml}$ hydrocortisone (SigmaAldrich, USA) and antibiotics. HSC-3, a highly invasive OSCC cell line, was obtained from Japan Health Sciences Foundation (Osaka, Japan) and cultured in DMEM/F-12 media (Invitrogen, USA) supplemented with 10\% FBS, $50 \mu \mathrm{g} / \mathrm{ml}$ ascorbic acid (SigmaAldrich, USA), $400 \mathrm{ng} / \mathrm{ml}$ hydrocortisone (Sigma-Aldrich, USA) and antibiotics. All cells were growth at $37^{\circ} \mathrm{C}$ in a humidified atmosphere of $5 \% \mathrm{CO}_{2}$. Cells were regularly tested for mycoplasma infection.

Quantitative PCR (qPCR). Total RNA from cell lines was isolated with TRIzol ${ }^{\circledR}$ reagent (Invitrogen, USA) according to the manufacturer's protocol. Following DNase I treatment in order to eliminate genomic DNA contamination, $1 \mu \mathrm{g}$ of total RNA per sample was used to generate cDNA using Oligo-dT (Invitrogen, USA) and reverse 
transcriptase (Superscript II RT enzyme, Invitrogen, USA). Resulting cDNAs were subjected to qPCR using specific primers and PowerUp ${ }^{\mathrm{TM}}$ SYBR $^{\circledR}$ Green Master Mix (Applied Biosystems) in the StepOnePlus Real Time PCR (Applied Biosystems). Gene expression was determined by the ${ }^{{ }^{\Delta}} \mathrm{CT}$ method and the housekeeping gene PPIA (cyclophilin A) was used as a reference gene for data normalization. All primers used in this study are described in Supplementary Table 1.

Stable short hairpin RNA (shRNA) knockdown of STC2. Stable knockdown of STC2 expression in OSCC cell lines was achieved by the construction of lentiviral vectors containing shRNA targeting human STC2 (MISSION ${ }^{\circledR}$ shRNA Lentiviral Transduction Particles, Sigma-Aldrich, USA) or scrambled control shRNA (MISSION ${ }^{\circledR}$ pLKO.1-puro Non-Mammalian shRNA Control, Sigma-Aldrich, USA) carrying a puromycin antibiotic resistance gene. Oligonucleotide sequence for STC2 shRNA (NM_003714.1)

\section{5'CCGGGAACAGTCTGAGTATTCTGATCTCGAGATCAGAATACTCAGACTGTTCTTT}

TTTG3'. In essence, SCC-15 and HSC-3 cells grown in a 12-well plate at confluence of $70 \%$ were incubated with control or STC2 shRNA lentiviral particles at a multiplicity of infection (MOI) of 1.5 in culture media containing $8 \mathrm{mg} / \mathrm{ml}$ of polybrene (Sigma-Aldrich, USA) for $4 \mathrm{~h}$. After washing with PBS, cells were cultured in fresh media for an additional period of $48 \mathrm{~h}$. Cells were then cultured for 10 days in the presence of $1 \mu \mathrm{g} / \mathrm{ml}$ of puromycin dihydrochloride (Sigma-Aldrich, USA) to select resistant cells. Efficacy of STC2 knockdown was determined by qPCR and western blot.

Western blot analysis. Proteins extracted from silenced cells were separated by $10 \%$ or $12 \%$ SDS-PAGE under reducing conditions and transferred onto nitrocellulose membranes. The membranes were blocked with $10 \%$ non-fat dry milk in PBS containing $0.1 \%$ Tween-20, rinsed in the same buffer, and incubated for $2 \mathrm{~h}$ with the primary antibodies: anti-STC2 (1:100, Abcam, USA), anti-AKT (1:1000, Cell Signaling, USA), 
anti-pAKT (pS473, 1:1000, Cell Signaling, USA), anti-mTOR (1:1000, Cell Signaling, USA), anti-pmTOR (pS2448, 1:1000, Cell Signaling, USA), anti-PI3K (1:1000, Cell Signaling, USA), anti-E-cadherin (1:1000, clone 24E10, Cell Signaling, USA), antivimentin (1:1000, clone D21H3, Cell Signaling, USA), anti-Snail1 (1:1000, clone C15D3, Cell Signaling, USA), anti-Snail2 (1:1000, clone C19G7, Cell Signaling, USA), anti- $\beta$ actin (1:30000, Sigma-Aldrich, USA) and anti-GAPDH (1:3000, Santa Cruz, USA). After washing, the protein bands were detected using enhanced chemiluminescence western blotting system (GE Healthcare, USA) and signals captured with an Alliance 9.7 instrument (UVITEC, UK).

Bromodeoxyuridine (BrdU) incorporation assay. Proliferation rates were determined by measuring BrdU incorporation into DNA using the Cell Proliferation ELISA BrdU (Colorimetric) kit (Roche Applied Science, Germany). Briefly, BrdU antigen was added to the cultures in $1: 10$ dilution and kept for $2 \mathrm{~h}$ at $37^{\circ} \mathrm{C}$ in $5 \% \mathrm{CO}_{2}$. After incubation, the medium was removed and manufacturer's protocol was followed. Absorbance was measured at $450 \mathrm{~nm}$ with correction at $655 \mathrm{~nm}$.

Apoptosis analysis. Apoptosis index was determined by annexin $\mathrm{V}$ labeling. Briefly, cells were harvested, washed and resuspended in the binding buffer (10 mM HEPES pH 7.4, $150 \mathrm{mM} \mathrm{NaCl}, 5 \mathrm{mM} \mathrm{KCl}, 1 \mathrm{mM} \mathrm{MgCl}_{2}$ and $1.8 \mathrm{mM} \mathrm{CaCl}_{2}$ ) containing annexin V-PE and 7-AAD (BD Biosciences, USA). Apoptosis was analyzed on a FACScalibur flow cytometer equipped with an argon laser (BD Biosciences, USA) and quantified as the number of annexin V-PE positive and 7-AAD negative cells divided by the total number of cells.

Invasion and migration assays. Transwell migration and invasion assays were performed in $6.5 \mathrm{~mm}$ inserts with $8 \mu \mathrm{m}$ pore size (Corning, USA). For invasion assay, membranes were coated with $50 \mu \mathrm{l}$ of myogel [17]. Starved cells were plated into the 
upper chamber in $200 \mu \mathrm{l}$ of serum-free DMEM/F12. As chemoattractant, $500 \mu \mathrm{l}$ of complete medium was used in the lower chamber. Experiment times varied between 24 $\mathrm{h}$ for migration and 48-72 $\mathrm{h}$ for invasion assays. Assessment of migration or invasion was performed by gently removing cell in the interior part of the insert with a cotton swab. Cells on the bottom of the membrane were fixed in 10\% formalin for $30 \mathrm{~min}$ and stained with $1 \%$ toluidine blue in $1 \%$ borax solution. The excess dye was washed out and cells were then eluted in 1\% SDS solution for $5 \mathrm{~min}$. Absorbance was measured at $655 \mathrm{~nm}$.

Gelatin zymography for MMP-2 and MMP-9. Zymography was performed with conditioned media of the cells. Briefly, samples were submitted to 1-D electrophoresis on $10 \%$ SDS-PAGE gels containing $1 \mathrm{mg} / \mathrm{ml}$ gelatin under nonreducing conditions. Gels were stained with Coomassie blue, and gelatinolytic activity was identified as clear bands against a blue background.

Tumorigenicity assay. To assess the growth of xenograft tumors in nude mice, HSC3 cells (HSC-3 shRNA Control and HSC-3 shRNA STC2) were injected s.c. in the flank of 12-week-old nude mice (10 animals per cell line). At 4-weeks, all mice were euthanized, and tumors and multiple organs were examined grossly, collected, fixed in $10 \%$ formalin and then embedded in paraffin. At this moment, tumor size was measured with a caliper, and volumes are reported as $\mathrm{mm}^{3}$, calculated by using the formula volume $=0.5 \times$ length $x$ width $^{2}$. Five-micrometer sections were stained with hematoxylin and eosin for histopathologic analysis and subjected to STC2 immunohistochemistry. The animal experiment was reviewed and approved by the Ethical Committee on Animal Research at the University of Campinas (protocol number 5279-1/2019).

Analysis of phosphorylated proteins by Luminex technology. Total proteins from shRNA Control and shRNA STC2 cells were extracted and subjected to analysis of the phosphorylated proteins CREB (pS133), ERK (pT185/pY187), JNK 
(pT183/pY185), p38 (pT180/pY182), p70 S6K (pT412), STAT3 (pS727), STAT5A/B (pY694/699), AKT (pS473) using a multiplex kit (Milliplex MAP Multi-Pathway \#48680MAG, Millipore, USA), according to the manufacturer's instructions. Positive and negative controls (cellular lysates provided by the kit) were included in all analyses.

Statistical analysis. Associations between immunoexpression of STC2 and clinicopathological parameters of the tumors were performed using cross-tabulation and chi-square test. Survival curves were constructed based on the Kaplan-Meier method and compared with the Log-rank test. For multivariate survival analysis, the Cox proportional hazard model with a stepwise method was applied. All functional assays were performed at least three times. Mann-Whitney $U$ test or one-way analysis of variance (ANOVA) with post-hoc comparisons based on the Tukey's multiple comparisons test were applied. P values $\leq 0.05$ were considered as significant.

\section{Results}

\section{STC2 expression is associated with worse outcome of patients with OSCC}

At first, we performed a meta-analysis with published microarray data compiled from Oncomine ${ }^{\circledR}$ Research Premium Edition database. Comparison across microarray gene expression studies showed that STC2 mRNA is significantly overexpressed in OSCC samples compared with normal oral mucosa $(p=0.01)$. The association between STC2 expression and clinicopathological characteristics was verified in the cohort containing 100 cases of OSCC (cohort 1). All cases showed cytoplasmatic staining of STC2 in the tumor cells, with variable distribution and intensity. A high expression of STC2 was detected in $64 \%$ of the tissue samples (Fig. 1A), while low expression was found in 36\% (Fig. 1B). As depicted in Table 1, the high expression of STC2 in OSCC tissues was significantly associated with advanced clinical stage $(p=0.02)$, and a tendency towards association was observed with recurrence $(p=0.07)$ and development of a second primary tumor $(p=0.06)$. 
We next assessed the association between STC2 expression and clinical prognosis of OSCC patients. Outcomes were categorized as disease-specific survival, time from treatment initiation until death due to cancer or last known date alive, and disease-free survival, time from treatment initiation until diagnosis of the first recurrence (local, regional or distant) or last follow-up information for those without recurrence. Only survivors with follow-up information of at least 5 years were included. In comparison with low expression, patients with high STC2 expression had a significantly shorten diseasespecific survival (HR: $2.68,95 \% \mathrm{Cl}: 1.56-4.62, \mathrm{p}=0.002)$ and a high risk of recurrence (disease-free survival), yielding a $\mathrm{HR}$ of 2.37 (95\% Cl: 1.20-4.69, $\mathrm{p}=0.02)$ (Table 2). On univariate analysis, significant associations between age $(p=0.02)$ and advanced clinical stage $(p=0.02)$ with shorten disease-specific survival were detected (Table 2). On multivariate survival analysis, age (HR: 1,95, 95\% Cl: 1.12-3.38, $\mathrm{p}=0.01)$ and STC2 expression (HR: $2.67,95 \% \mathrm{Cl}: 1.37-5.21, \mathrm{p}=0.001)$ were independently associated with cancer-specific survival, whereas for disease-free survival, only STC2 (HR: 2.80, 95\% Cl: 1.07-5.71, $p=0.03$ ) was significantly associated (Table 3 ).

\section{Validation of association of STC2 with poor survival in an independent cohort}

To confirm our findings, the expression levels of STC2 were investigated in an independent set of OSCCs (cohort 2; details provided in materials and methods section), applying a different anti-STC2 polyclonal antibody. Patients with high STC2 expression showed a 5 -year disease-specific survival of $46.0 \%$ compared with $84.5 \%$ for patients with low STC2 immunoreactivity, yielding a HR of $2.68(95 \% \mathrm{Cl}: 1.14-6.32, \mathrm{p}=0.02$, Fig. 2A). After 5 years, $88.5 \%$ of patients classified with low STC2 expression remained without recurrence compared with $48.7 \%$ of those with high STC2 expression (HR: 2.66 , 95\% Cl: 1.16-6.14, $p=0.01$, Fig. 2B).

\section{Efficiency of STC2 knockdown in OSCC cells}


We investigated the expression of STC2 in one normal oral keratinocyte and five OSCC cell lines. The STC2 mRNA levels were significantly higher in the OSCC cell lines SCC-4 $(p<0.01)$, SCC-9 ( $p<0.01)$, SCC-15 $(p<0.0001)$ and HSC-3 $(p<0.001)$ compared with the spontaneously immortalized, but not transformed oral keratinocyte cell line HGK (SFig. 1). Although high, the expression of STC2 in SCC-25 did not reach a significant level. Considering SCC-15 and HSC-3 presented the highest STC2 expression among OSCC cell lines, they were chosen for testing the effects of STC2 knockdown. We then transduced SCC-15 and HSC-3 with a retroviral vector encoding a STC2 shRNA. Compared to control cells (transduced with a universal shRNA control), STC2 mRNA and protein levels were significant lower in STC2-silenced cells (Fig. 3).

\section{STC2 controls proliferation, apoptosis, migration and invasion of OSCC cells}

shRNA Control and shRNA STC2 cells were analyzed for cell proliferation, apoptosis, migration and invasiveness. As shown in Fig. 4A, the proliferation of SCC15 ( $73 \%$ reduction, $\mathrm{p}<0.0001)$ and $\mathrm{HSC}-3 \quad(\sim 64 \%$ reduction, $\mathrm{p}<0.001)$ was significantly reduced following STC2 knockdown. The annexin V/7-AAD labeling assay was employed to measure apoptosis of the shRNA. Flow cytometry revealed that the number of apoptotic cells in the cells expressing the specific shRNA against STC2 was significantly higher compared to respective controls (Fig. 4B). For SCC-15 shRNA STC2 cells, the increase in apoptosis rate was of approximately $40 \%(p<0.01)$ and for HSC-3 shRNA STC2 cells was approximately $19 \%(p<0.01)$. Both migration and invasion were attenuated by STC2 knockdown. Compared to shRNA Control cells, the migration of SCC-15 shRNA STC2 cells was reduced in 55\% ( $p<0.001)$, whereas the reduction of HSC-3 shRNA STC2 cell migration was approximately of $46 \%(p<0.01)$ (Fig. 4C). Fewer SCC-15 ( $~ 50 \%$ reduction, $\mathrm{p}<0.001)$ and HSC-3 ( 54\% reduction, $\mathrm{p}<0.001)$ cells with STC2 knockdown invaded the extracellular matrix compared to their corresponding controls (Fig. 4D). 


\section{STC2 is associated with EMT}

To investigate whether STC2 is associated with acquisition of EMT properties, we assessed the expression of EMT markers, including epithelial marker E-cadherin and mesenchymal marker vimentin, as well as EMT transcription factors, after knockdown STC2 expression. As indicated in Fig. 5A, cells expressing STC2-targeting shRNA had significantly higher mRNA levels of E-cadherin ( $p<0.01$ for SCC-15 cells and $p<0.001$ for HSC-3 cells) and significantly lower expression of vimentin ( $p<0.05$ for both SCC-15 and HSC-3 cells) compared to control cells. Analysis of EMT transcription factors showed a consistent decrease in the expression of Snail1 $(p<0.0001$ for both SCC-15 and HSC3), Twist ( $p<0.05$ for SCC-15 and $p<0.01$ for HSC-3) and Zeb2 ( $<<0.001$ for both SCC15 and HSC-3) in shRNA cells compared with controls (Fig. 5B). Zeb1 expression was only significantly downregulated in HSC-3 cells $(p<0.001)$, whereas no effects on Snail2 were detected in both cell lines (Fig. 5B). In the western blot analysis, levels of Ecadherin were increased and levels of vimentin, Snail1 and Snail2 were decreased in SCC-15 shRNA STC2 cells compared to SCC-15 shRNA Control cells (Fig. 5C). In addition, we investigated MMP-2 and MMP-9 by qPCR and zymography. Levels of MMP2 and MMP-9 mRNA were significantly lower in STC2-silenced cells compared to their corresponding control cells (Fig. 5D). In consonance, the gelatinolytic activities of MMP2 (band with $72 \mathrm{kDa}$ ) and MMP-9 (band with $92 \mathrm{kDa}$ ) were lower in conditioned medium from shRNA STC2 cells compared to shRNA Control cells (Fig. 5E).

\section{Expression of STC2 is reactivated in xenograft tumors}

To further investigate the effects of STC2 on tumor growth in vivo, HSC-3 shRNA control and HSC-3 shRNA STC2 cells were injected subcutaneously into nude mice. The tumor nodules were visible in all mice, but no significant differences in volume were found (SFig. 2). The histological features of tumors were quite similar, and immunohistochemical analysis showed a clear cytoplasmic STC2 staining in HSC-3 shRNA STC2 cells, mainly in the peripheral cells of the tumor islands. Although some 
cells were completely negative, a reactivation of STC2 in vivo was observed in the tumors formed by shRNA STC2 cells (SFig. 3).

\section{Cell signaling in STC2 knockdown cells}

A previous study demonstrated that the pro-tumorigenic effects of STC2 are mediated by PI3K-AKT-Snail signaling [14]. We therefore examined the PI3K-AKTmTOR signaling pathway and their phosphorylation status through western blot. No differences were observed in both SCC-15 and HSC-3 control and silencing cells (Fig. 6A). In order to further investigate the effects of STC2, we analyzed key proteins associated with different pathways using a multiplex assay containing phosphorylated CREB (pS133), ERK (pT185/pY187), JNK (pT183/pY185), p38 (pT180/pY182), p70 S6K (pT412), STAT3 (pS727), STAT5A/B (pY694/699), AKT (pS473). None of the investigated proteins was consistently and statistically different between shRNA Control and shRNA STC2 cells, including AKT (Fig. 6B).

\section{Discussion}

Although STC2 was originally associated with calcium/phosphate regulation during mineralization, it has been speculated that it is actually an oncoprotein since its overexpression in many cancer types can predict outcome. Nonetheless, studies on STC2 roles in OSCC are still limited. In this study, we found that STC2 is overexpressed in OSCCs in comparison with normal oral mucosa, and its expression is associated with advanced clinical stage, shortened disease-free survival and poor disease-specific survival. These results are in line with previous ones regarding many solid cancers [10] and with the findings of Yang and collaborators [14] on 298 patients with HNSCC (tumors from oral cavity, oropharynx, pharynx and larynx). Interestingly, the expression levels of STC2 were significantly related to the clinical stage of tumor but there were no large alterations in the hazard ratios and its significance on multivariate compared to univariate analysis in our survival analysis, and our findings were validated with a different antibody 
in an independent cohort, supporting that STC2 is a promising and independent prognostic biomarker for OSCCs.

Modulation of STC2 expression has been investigated in different contexts and cell lines. In this study, we found that STC2 knockdown inhibits proliferation, migration and invasion, and promotes apoptosis of OSCC cells. In consonance with our results, previous studies have demonstrated that STC2 regulates proliferation and colony formation of lung and cervical cancer cells $[8,18]$, and STC2-silencing reduces the migration and invasion of colorectal cancer cells [19]. Moreover, loss of STC2 increased radiation sensitivity of nasopharyngeal carcinoma cells, resulting in accumulation of the cells at $G_{1}$ and $G_{2} / M$ phases of the cell cycle [20]. Through inhibition of STC2, miR-485$5 p$, miR-184, miR-206 and miR-1-3p inhibited proliferation, migration and invasion of hepatocellular carcinoma, glioblastoma, HNSCC and gastric cancer cells, respectively [15,21-23]. One recent study showed that STC2 overexpression in colon adenocarcinoma, which allows its pro-tumorigenic roles, is dependent on Sp1 promoter activation [24]. In contrast, overexpression of STC2 resulted in a significant impairment of growth, migration and invasion in breast cancer cells $[25,26]$. In mouse xenograft models of colorectal cancer [9] and HNSCC [14] and in neuroblastoma experimental formation on the chick chorioallantoic membrane [27], STC2 accelerated tumor growth and facilitated early metastasis. However, in our xenograft model, the expression of STC2 was reactivated in most of the peripheral cells of tumor islands, and the cells transduced with STC2 shRNA had quite similar tumor growth pattern than control cells. It is possible that the complex in vivo tumor microenvironment set in this xenograft model produces regulatory factors that reactivated STC2, such as hypoxia inducible factor 1 (HIF-1), a STC2 target gene that promotes proliferation and invasion in hypoxia, a feature of this xenograft model $[28,29]$. Our findings support that overexpression of STC2 promotes oral tumorigenesis by regulation of proliferation, survival, migration and invasion of OSCC cells, but STC2 might play different regulatory functions in the context of cell tumor origin. 
EMT comprises the biological process by which cells transit between epithelial and mesenchymal states and may acquire potent pro-tumorigenic features, including motility, invasiveness, stemness, drug-resistance and the ability to form metastases [30]. This transition can be regulated at multiple levels, but transcriptional control of gene expression by EMT-inducing transcription factors, including Snails, Zebs and Twist, is generally considered the master step in this process [31]. The main hallmarks of EMT are the loss of the epithelial cell-cell adhesion molecule E-cadherin and acquisition of mesenchymal cell marker vimentin, inducing phenotypical plasticity of cells [32]. Downregulation of STC2 was associated with gain of E-cadherin expression and loss of vimentin, suggesting EMT regulation. In addition, STC2-knockdown cells showed consistent inhibition of MMP-2 and MMP-9 and of EMT-inducing transcription factors Snail1, Twist and Zeb2. Consistent with our findings, previous studies have revealed that overexpression of STC2 may trigger EMT and MMP expression in ovarian [33], colorectal [19,34] and HNSCC [14]. In this context, STC2 was closely related with chemotherapeutic drug resistance in cervical, liver and colorectal cancer $[18,34,35]$, and cells overexpressing STC2 showed elevated expression of the pluripotency and selfrenewal markers Oct4 and Nanog [7]. Yang and collaborators [14] reported that STC2 could promote EMT in vitro through activating PI3K-AKT signaling. Unexpectedly, we were unable to detect any alteration in expression or phosphorylation of $\mathrm{PI} 3 \mathrm{~K}, \mathrm{AKT}$ and mTOR concomitant with STC2 downregulation. Other signaling pathways frequently altered in OSCCs, including CREB, ERK, JNK, p38, p70 S6K, STAT3 and STAT5A/B, were not affected by silencing of STC2. Based on our results, we concluded that overexpression of STC2 in OSCC cells plays an important role on acquisition of EMT properties, but this effect is independent of PI3K-AKT-mTOR pathway.

In closing, our findings show that STC2 is upregulated in patients with OSCC and its overexpression is significantly and independently associated with relapse and poor outcome. In vitro downregulation of STC2 drove proliferation, survival and EMT properties associated with migration and invasiveness of OSCC cells. Therefore, the 
potential clinical applications of STC2 as a prognostic marker and as a therapeutic target should be considered in OSCC.

\section{Conflicts of interest}

The authors have no conflicts of interest to declare.

\section{Funding}

This work was supported by grants from Fundação de Amparo à Pesquisa do Estado de São Paulo - FAPESP (2018/16077-6 for RDC). MRD (2017/26764-8) is research fellow supported by FAPESP, and LMPR received a grant from the Fundação de Amparo à Pesquisa do Estado de Minas Gerais - FAPEMIG (APQ 00205.16).

\section{Authors contributions}

AFC, MRD, CEO, DCB, CBD, GAB, ENSG and RDC carried out data acquisition and analysis. IS-C and LMRP have contributed with the samples and their clinical information. EG, TAS, RAF and HCG have participated in the design of the study. RDC has designed and implemented the research protocol, and drafted the manuscript. All authors have critically revised the manuscript.

\section{References}

[1] F. Bray, J. Ferlay, I. Soerjomataram, R.L. Siegel, L.A. Torre, A. Jemal. Global cancer statistics 2018: GLOBOCAN estimates of incidence and mortality worldwide for 36 cancers in 185 countries. CA Cancer J Clin. 68 (2018) 394-424.

[2] A.C. Chi, T.A. Day, and B.W. Neville. Oral cavity and oropharyngeal squamous cell carcinoma-an update. CA Cancer J Clin. 65 (2015) 401-421. 
[3] L. Hingsammer, T. Seier, J. Ikenberg, P. Schumann, D. Zweifel, M. Rücker, M. Bredell, M. Lanzer. The influence of lymph node ratio on survival and disease recurrence in squamous cell carcinoma of the tongue. Int J Oral Maxillofac Surg. 48 (2019): 851-856.

[4] A. Almangush, I. Heikkinen, A.A. Mäkitie, R.D. Coletta, E. Läärä, I. Leivo, T. Salo. Prognostic biomarkers for oral tongue squamous cell carcinoma: a systematic review and meta-analysis. Br J Cancer. 117 (2017) 856-866.

[5] B.H. Yeung, A.Y. Law, C.K. Wong. Evolution and roles of stanniocalcin. Mol Cell Endocrinol. 349 (2012): 272-80.

[6] S.J. Chu, J. Zhang, R. Zhang, W.W. Lu, J.S. Zhu. Evolution and functions of stanniocalcins in cancer. Int J Immunopathol Pharmacol. 28 (2015) 14-20.

[7] P.H. Kim, S.S. Na, B. Lee, J.H. Kim, J.Y. Cho. Stanniocalcin 2 enhances mesenchymal stem cell survival by suppressing oxidative stress. BMB Rep. 48 (2015): 702-707.

[8] S.S. Na, M.B. Aldonza, H.J. Sung, Y.I. Kim, Y.S. Son, S. Cho, J.Y. Cho. Stanniocalcin2 (STC2): A potential lung cancer biomarker promotes lung cancer metastasis and progression. Biochim Biophys Acta. 1854 (2015): 668-676.

[9] B. Chen, X. Zeng, Y He, X Wang, Z. Liang, J. Liu, P. Zhang, H. Zhu, N. Xu, S. Liang. STC2 promotes the epithelial-mesenchymal transition of colorectal cancer cells through AKT-ERK signaling pathways. Oncotarget. 7 (2016) 71400-71416.

[10] L. Hu, Y. Zha, F. Kong, Y. Pan. Prognostic value of high stanniocalcin 2 expression in solid cancers: A meta-analysis. Medicine (Baltimore). 98 (2019): e17432.

[11] S. Esseghir, A. Kennedy, P. Seedhar, A. Nerurkar, R. Poulsom, J.S. Reis-Filho, C.M. Isacke. Identification of NTN4, TRA1, and STC2 as prognostic markers in breast cancer in a screen for signal sequence encoding proteins. Clin Cancer Res. 13 (2007): 3164-73.

[12] J.R. Todd, K.A. Ryall, S. Vyse, J.P. Wong, R.C. Natrajan, Y. Yuan, A.C. Tan, P.H. Huang. Systematic analysis of tumour cell-extracellular matrix adhesion identifies 
independent prognostic factors in breast cancer. Oncotarget. 7 (2016): 6293962953.

[13] C. Coulson-Gilmer, M.P. Humphries, S. Sundara Rajan, A. Droop, S. Jackson, A. Condon, G. Cserni, L.B. Jordan, L.J. Jones, R. Kanthan, et al. Stanniocalcin 2 expression is associated with a favourable outcome in male breast cancer. J Pathol Clin Res. 4 (2018) 241-249.

[14] S. Yang, Q. Ji, B. Chang, Y. Wang, Y. Zhu, D. Li, C. Huang, Y. Wang, G. Sun, L. Zhang. STC2 promotes head and neck squamous cell carcinoma metastasis through modulating the PI3K/AKT/Snail signaling. Oncotarget. 8 (2017): 5976-5991.

[15] T. Li, Y. Qin, Z. Zhen, H. Shen, T. Cong, E. Schiferle, S. Xiao. Long non-coding RNA HOTAIR/microRNA-206 sponge regulates STC2 and further influences cell biological functions in head and neck squamous cell carcinoma. Cell Prolif. 52 (2019): e12651.

[16] I. Sawazaki-Calone, A. Rangel, A.G. Bueno, C.F. Morais, H.M. Nagai, R.P. Kunz, R.L. Souza, L. Rutkauskis, T. Salo, A. Almangush, et al. The prognostic value of histopathological grading systems in oral squamous cell carcinomas. Oral Dis. 21 (2015): 755-761.

[17] T. Salo, M. Sutinen, E. Hoque Apu, E. Sundquist, N.K. Cervigne, C.E. de Oliveira, S.U. Akram, S. Ohlmeier, F. Suomi, L. Eklund, et al. A novel human leiomyoma tissue derived matrix for cell culture studies. BMC Cancer. 15 (2015): 981.

[18] Y. Wang, Y. Gao, H. Cheng, G. Yang, W. Tan. Stanniocalcin 2 promotes cell proliferation and cisplatin resistance in cervical cancer. Biochem Biophys Res Commun. 466 (2015): 362-368.

[19] Q. Li, X. Zhou, Z. Fang, Z. Zan. Effect of STC2 gene silencing on colorectal cancer cells. Mol Med Rep. 20 (2019): 977-984.

[20] H. He, S. Qie, Q. Guo, S. Chen, C. Zou, T. Lu., Y. Su, J. Zong, H. Xu, D. He, et al. Stanniocalcin 2 (STC2) expression promotes post-radiation survival, migration and 
invasion of nasopharyngeal carcinoma cells. Cancer Manag Res. 11 (2019): 64116424.

[21] G.X. Guo, Q.Y. Li, W.L. Ma, Z.H. Shi, X.Q. Ren. MicroRNA-485-5p suppresses cell proliferation and invasion in hepatocellular carcinoma by targeting stanniocalcin 2 . Int J Clin Exp Pathol. 8 (2015): 12292-12299.

[22] Feng, L., Ma, J., Ji, H., Liu, Y., Hu, W. (2018) MiR-184 retarded the proliferation, invasiveness and migration of glioblastoma cells by repressing stanniocalcin-2. Pathol Oncol Res, 24(4): 853-860.

[23] J. Ke, B.H. Zhang, Y.Y. Li, M. Zhong, W. Ma, H. Xue, Y. Wen, Y.D. Cai. MiR-1-3p suppresses cell proliferation and invasion and targets STC2 in gastric cancer. Eur Rev Med Pharmacol Sci. 23 (2019): 8870-8877.

[24] J.B. Li, Z.X. Liu, R. Zhang, S.P. Ma, T. Lin, Y.X. Li, S.H. Yang, W.C. Zhang, Y.P. Wang. Sp1 contributes to overexpression of stanniocalcin 2 through regulation of promoter activity in colon adenocarcinoma. World J Gastroenterol. 25 (2019): 27762787.

[25] S. Raulic, Y. Ramos-Valdes, G.E. DiMattia. Stanniocalcin 2 expression is regulated by hormone signalling and negatively affects breast cancer cell viability in vitro. $\mathrm{J}$ Endocrinol.197 (2008): 517-529.

[26] J. Hou, Z. Wang, H. Xu, L. Yang, X. Yu, Z. Yang, Y. Deng, J. Meng, Y. Feng, X. Guo, et al. Stanniocalicin 2 suppresses breast cancer cell migration and invasion via the PKC/claudin-1-mediated signaling. PLoS One. 10 (2015): e0122179.

[27] S. Volland, W. Kugler, L. Schweigerer, J. Wilting, J. Becker. Stanniocalcin 2 promotes invasion and is associated with metastatic stages in neuroblastoma. Int $\mathrm{J}$ Cancer. 125 (2009): 2049-2057.

[28] A.Y. Law, C.K. Wong. Stanniocalcin-2 is a HIF-1 target gene that promotes cell proliferation in hypoxia. Exp Cell Res. 316 (2010): 466-476.

[29] S. Miyazaki, H. Kikuchi, I. lino, T. Uehara, T. Setoguchi, T. Fujita, Y. Hiramatsu, M. Ohta, K. Kamiya, K. Kitagawa. Anti-VEGF antibody therapy induces tumor hypoxia 
and stanniocalcin 2 expression and potentiates growth of human colon cancer xenografts. Int J Cancer. 135 (2014): 295-307.

[30] Y. Zhang, R.A. Weinberg. Epithelial-to-mesenchymal transition in cancer: complexity and opportunities. Front Med. 12 (2018): 361-373.

[31] P. Simeone, M. Trerotola, J. Franck, T. Cardon, M. Marchisio, I. Fournier, M. Salzet, M. Maffia, D. Vergara. The multiverse nature of epithelial to mesenchymal transition. Semin Cancer Biol, 58 (2019): 1-10.

[32] M. Pal, S. Bhattacharya, G. Kalyan, S. Hazra. Cadherin profiling for therapeutic interventions in epithelial mesenchymal transition (EMT) and tumorigenesis. Exp Cell Res. 368 (2018): 137-146.

[33] A.Y. Law, C.K. Wong. Stanniocalcin-2 promotes epithelial-mesenchymal transition and invasiveness in hypoxic human ovarian cancer cells. Exp Cell Res. 316 (2010): 3425-34.

[34] H. Cheng, Z. Wu, C. Wu, X. Wang, S.S. Liow, Z. Li, Y.L. Wu. Overcoming STC2 mediated drug resistance through drug and gene co-delivery by PHB-PDMAEMA cationic polyester in liver cancer cells. Mater Sci Eng C Mater Biol Appl. 83 (2018) 210-217.

[35] Q. Yuan, L. Zhan, L.L. Zhang, Q. Wang, J. Liu, Z.Y. Jiang, X.M. Hu, X.C. Yuan. Stanniocalcin 2 induces oxaliplatin resistance in colorectal cancer cells by upregulating P-glycoprotein. Can J Physiol Pharmacol. 94 (2016): 929-935. 


\section{Figure legends}

Fig. 1. Immunoexpression of STC2 in OSCCs. Representative immunohistochemical analysis of STC2 in OSCC specimens. OSCC tumor cells showed variable distribution and intensity of STC2. (A) OSCC specimen classified as low STC2 expression and (B) sample with high expression of STC2.

Fig. 2. Kaplan-Meier curves. Curves for cancer-specific survival (A) and disease-free survival (B) of patients with OSCC of cohort 2 based in STC2 expression levels.

Fig. 3. STC2 knockdown efficiency in SCC-15 and HSC-3 cells. Cells were transduced with lentivirus expressing shRNA sequences against STC2 (shRNA STC2 cells) and control (shRNA Control cells) as outlined in the methods. shRNA STC2 cells showed a marked reduction in both mRNA $(A)$ and protein levels $(B)$ when compared with shRNA Control cells. ${ }^{*} \mathrm{p}<0.0001$

Fig. 4. Knockdown of STC2 modulates proliferation, apoptosis, migration and invasion of OSCC cells. (A) Downregulation of STC2 significantly inhibited the proliferative potential of SCC-15 and HSC-3, as revealed decreased BrdU incorporation.

(B) The proportion of apoptotic cells was increased in shRNA STC2 cells compared to controls, as assessed by annexin V/7AAD binding assay. (C) Migration of SCC-15 and HSC-3 cells was significantly decreased by STC2-specific shRNA, as revealed by transwell migration assay. (D) Invasion of SCC-15 and HSC-3 cells was significantly inhibited after STC2 knockdown. ${ }^{*} \mathrm{p}<0.01,{ }^{* *} \mathrm{p}<0.001,{ }^{* * *} \mathrm{p}<0.0001$

Fig. 5. Modulation of STC2 mRNA levels affects epithelial-mesenchymal transitionrelated markers. (A) Downregulation of STC2 significantly increased the expression of E-cadherin while reduced vimentin in both SCC-15 and HSC-3 cells. (B) shRNA STC2 cells showed consistent decrease in the expression of Snail1, Twist and Zeb2 compared 
with control cells. Zeb1 expression was only significantly downregulated in HSC-3 cells. (C) Western blot analysis confirmed STC2 downregulation in SCC-15 cells is accompanied by increased levels of E-cadherin and decreased levels of vimentin, Snail1 and Snail2. (D) Downregulation of STC2 significantly decreased the expression of MMP2 and MMP-9 in SCC-15 and HSC-3 cells as determined by qPCR. (E) Zymography analysis of MMPs secreted by OSCC cells showed the inhibition of gelatinolytic activity of MMP-2 and MMP-9 in shRNA STC2 cells. ${ }^{*} \mathrm{p}<0.05,{ }^{* *} \mathrm{p}<0.01,{ }^{* * *} \mathrm{p}<0.001$, ${ }^{* \star * *} p<0.0001$

Fig. 6. (A) Effects of STC2 knockdown on expression and phosphorylation of PI3KAKT-mTOR signaling proteins. Western blotting of PI3K and both phosphorylated and total AKT and mTOR in shRNA Control and shRNA STC2 cells. (B) Activation of keyproteins related to CREB, ERK, JNK, p38, p70 S6K, STAT3 and STAT5A/B pathway. Values represent mean \pm standard derivation of 3 independent experiments for each cell line.

\section{Supplementary figure legends}

SFig. 1. STC2 is overexpressed in OSCC-derived cell lines. Total RNA from the normal human gingival keratinocyte cell line (HGK) and from 5 human OSCC cell lines (SCC-4, SCC-9, SCC-15, SCC-25 and HSC-3) were converted in CDNA and subjected to qPCR. The STC2 mRNA levels were significantly higher in OSCC cells lines than in HGK, with exception of SCC-25. $8 p<0.01,{ }^{* *} p<0.0001$.

SFig. 2. The volume of xenograft tumors formed by HSC-3 shRNA Control and HSC-3 shRNA STC2 cells. No differences in volume of tumors formed by HSC-3 shRNA Control and HSC-3 shRNA STC2 cells were observed. 
SFig. 3. Representative images of the xenograft tumors formed by HSC-3 shRNA Control cells (A and C) and HSC-3 shRNA STC2 cells (B and D). Tumors showed similar histological features, and unexpectedly, the levels of STC2 were reactivated in the peripheral HSC-3 shRNA STC2 cells of the tumor islands. 


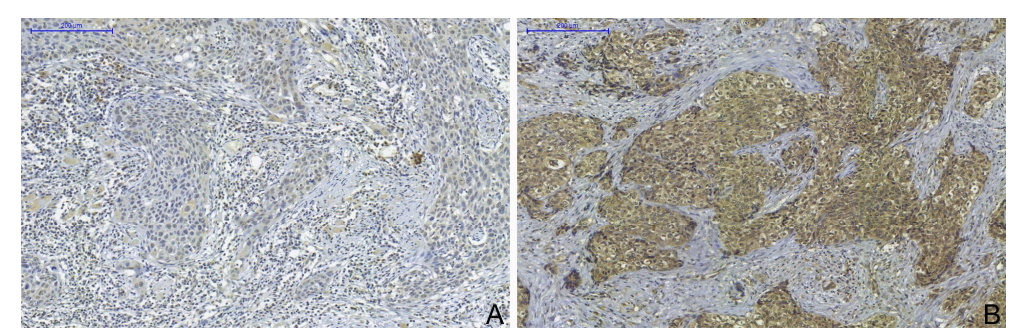



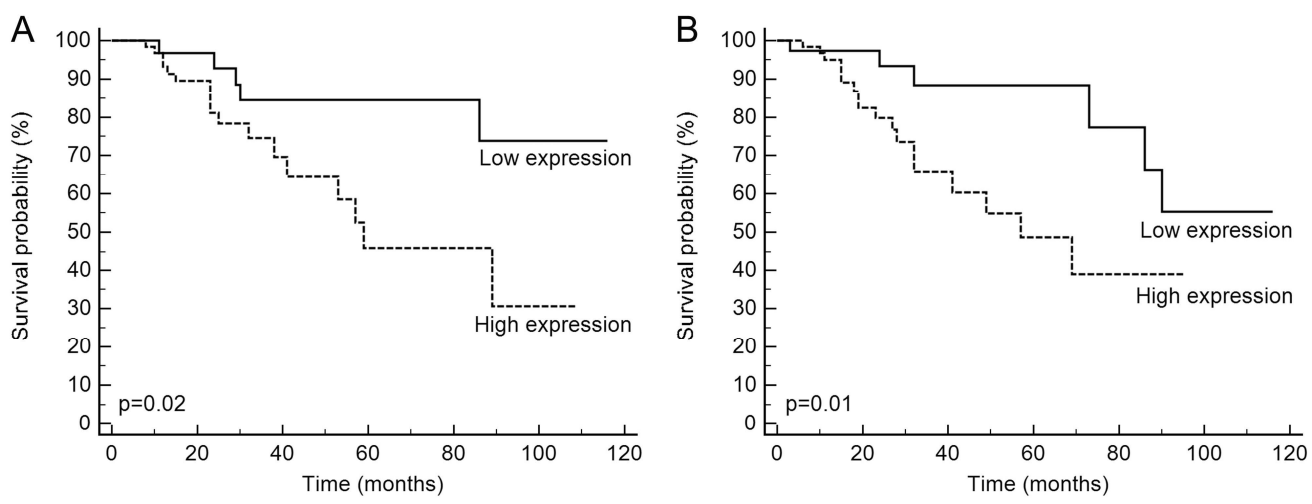


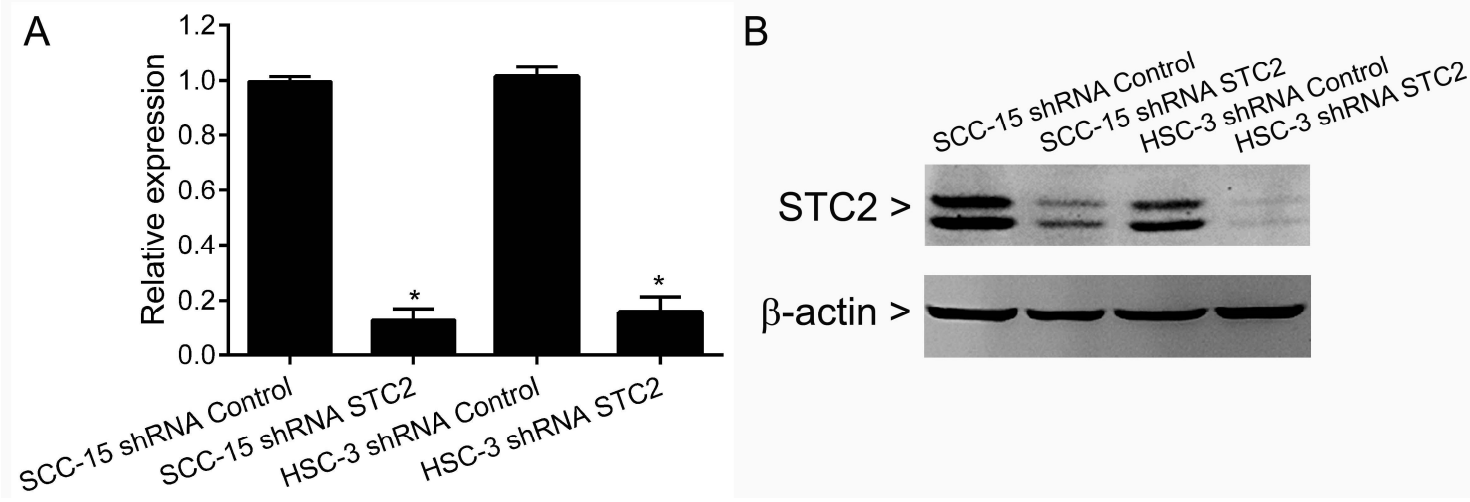



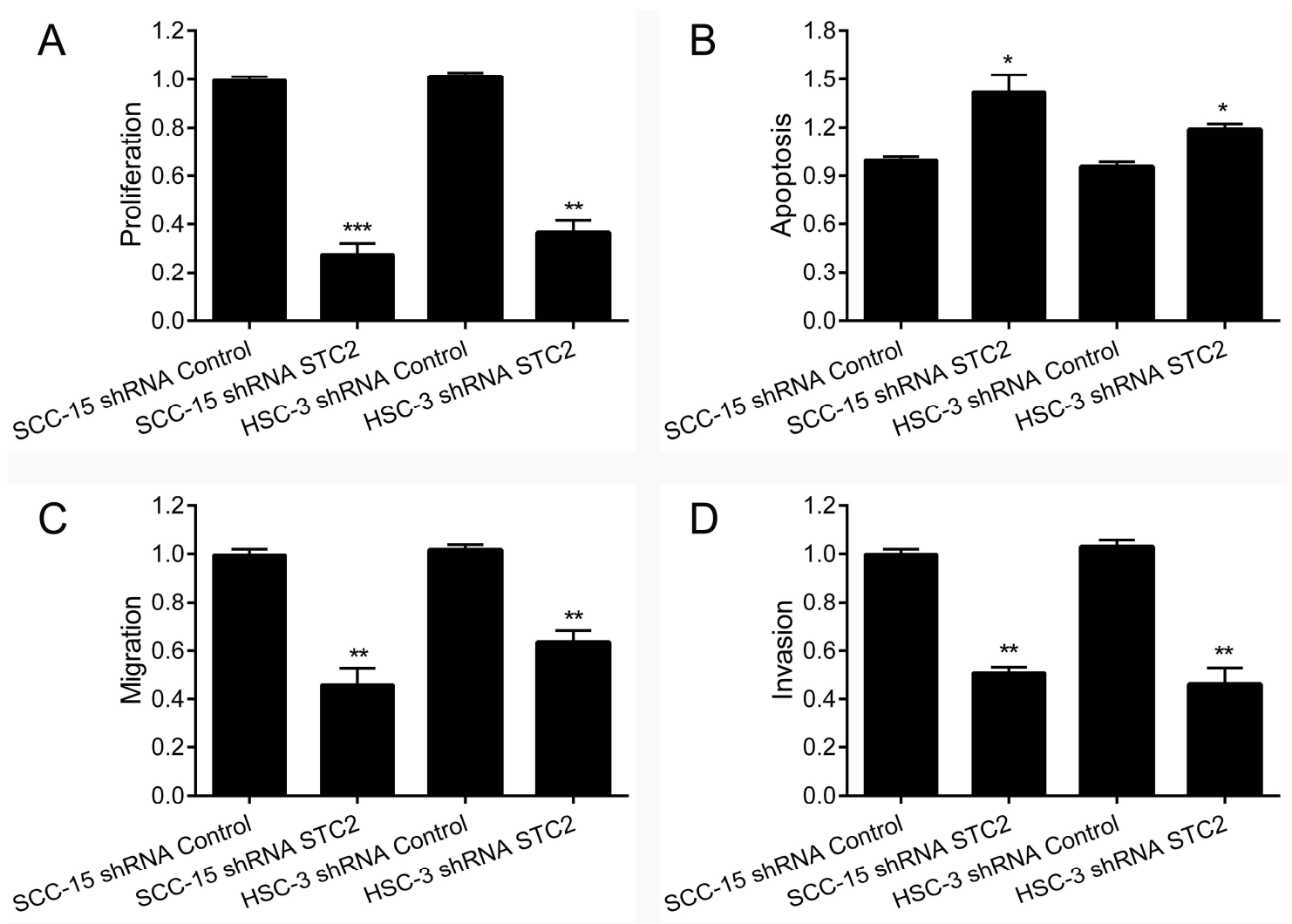

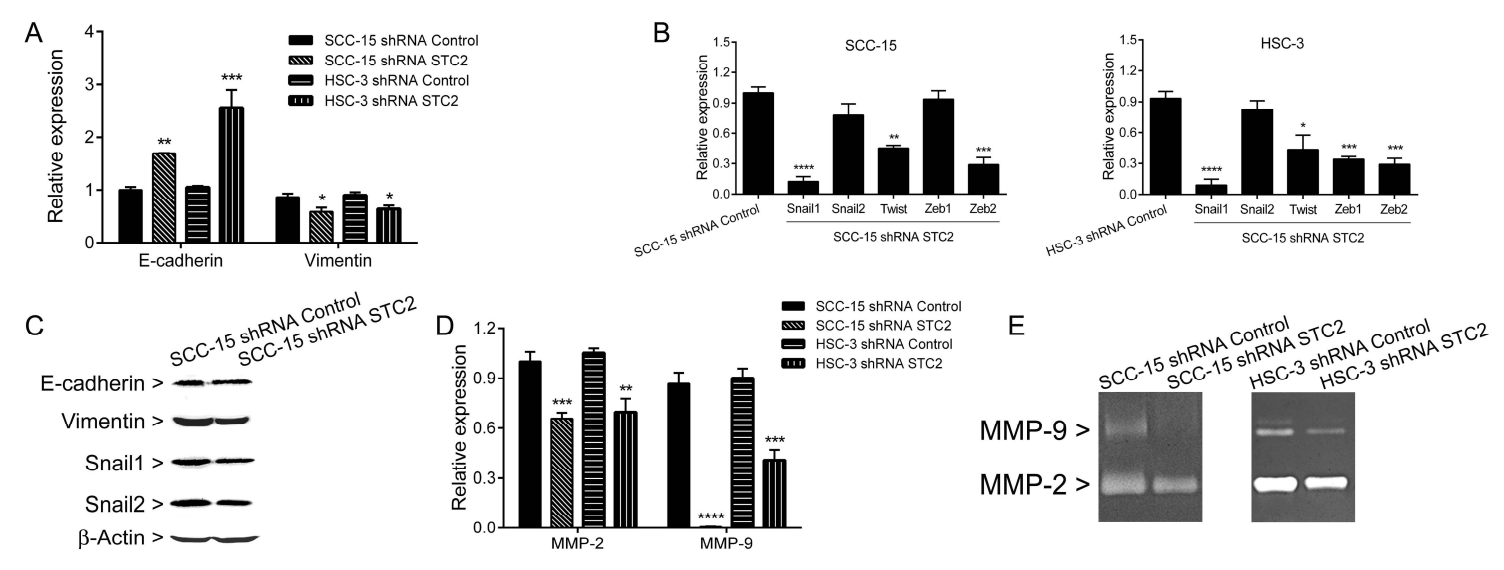


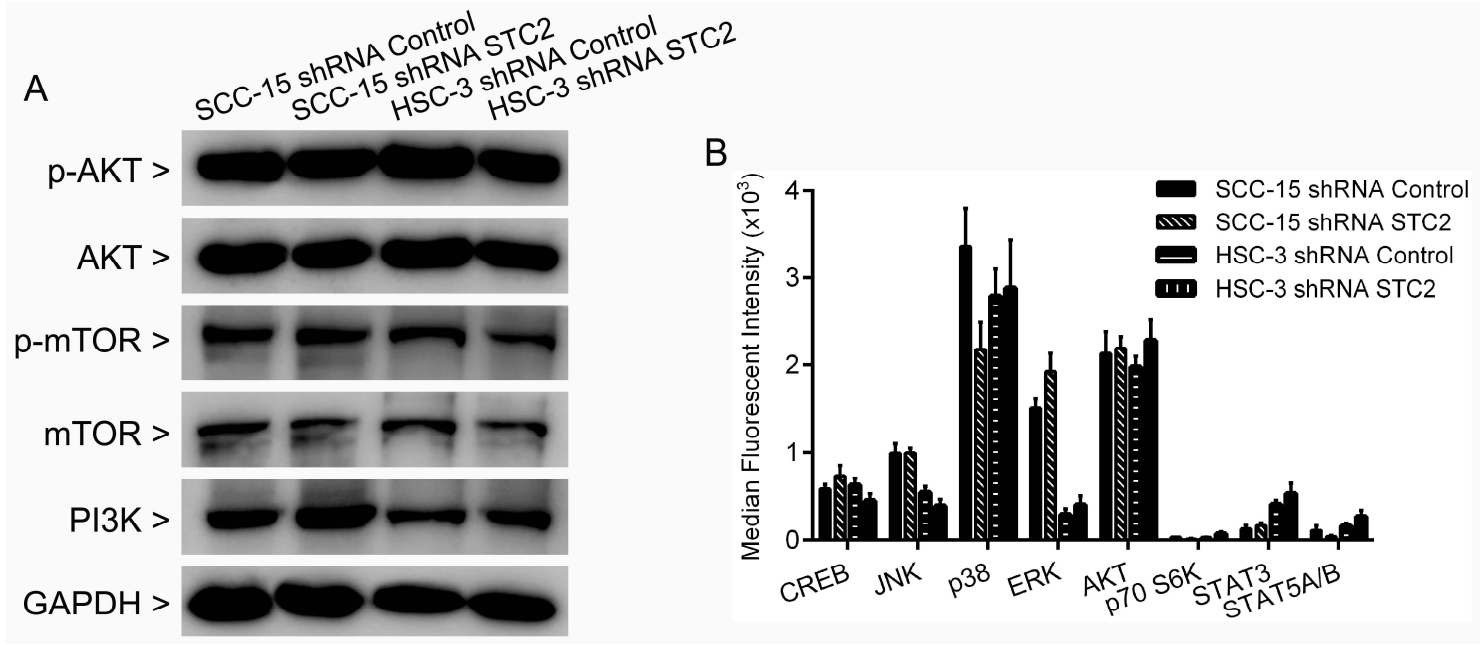


Table 1. Association of the clinicopathological parameters of the OSCC with the immunohistochemical expression of stanniocalcin 2 (STC2).

\begin{tabular}{|c|c|c|c|}
\hline Parameter & $\begin{array}{c}\text { Low STC2 } \\
\mathrm{n}(\%)\end{array}$ & $\begin{array}{c}\text { High STC2 } \\
\mathrm{n}(\%)\end{array}$ & $\mathrm{p}$ value \\
\hline \multicolumn{4}{|l|}{ Age } \\
\hline$<57$ years & $18(50)$ & $31(48.4)$ & \\
\hline$\geq 57$ years & $18(50)$ & $33(51.6)$ & 0.88 \\
\hline \multicolumn{4}{|l|}{ Gender } \\
\hline Male & $30(83.3)$ & $53(82.8)$ & \\
\hline Female & $6(16.7)$ & $11(17.2)$ & 0.94 \\
\hline \multicolumn{4}{|l|}{ Smoking habit } \\
\hline No & $5(16.1)$ & $8(15.7)$ & \\
\hline Yes & $26(83.9)$ & 43 (84.3) & 0.96 \\
\hline \multicolumn{4}{|l|}{ Drinking habit } \\
\hline No & $8(27.6)$ & $13(29.5)$ & \\
\hline Yes & $21(72.4)$ & $31(70.5)$ & 0.85 \\
\hline \multicolumn{4}{|l|}{ Clinical stage } \\
\hline Early $(I+I I)$ & $22(62.9)$ & $24(38.1)$ & \\
\hline Advanced (III + IV) & $13(37.1)$ & 39 (61.9) & 0.02 \\
\hline \multicolumn{4}{|l|}{ Tumor site } \\
\hline Tongue & $19(52.8)$ & $28(43.8)$ & \\
\hline Others & $17(47.2)$ & $36(56.2)$ & 0.38 \\
\hline \multicolumn{4}{|l|}{ Treatment } \\
\hline Surgery & $14(38.9)$ & $26(40.6)$ & \\
\hline Surgery + Radiotherapy & 19 (52.8) & $32(50)$ & \\
\hline Surgery + Radiotherapy + Chemotherapy & $3(8.3)$ & $6(9.4)$ & 0.96 \\
\hline \multicolumn{4}{|l|}{ Histological grade } \\
\hline Well-differentiated + Moderately-differentiated & $34(94.4)$ & $54(84.4)$ & \\
\hline Poorly-differentiated & $2(5.6)$ & $10(15.6)$ & 0.13 \\
\hline \multicolumn{4}{|l|}{ Margin status } \\
\hline$\geq 5 \mathrm{~mm}$ & $35(100)$ & $60(95.2)$ & \\
\hline$<5 \mathrm{~mm}$ & 0 & $3(4.8)$ & 0.19 \\
\hline \multicolumn{4}{|l|}{ Recurrence } \\
\hline No & $27(77.11)$ & $38(59.4)$ & \\
\hline Yes & $8(22.9)$ & $26(40.6)$ & 0.07 \\
\hline \multicolumn{4}{|l|}{ Second Primary Tumor } \\
\hline No & $24(68.6)$ & $54(84.4)$ & \\
\hline Yes & $11(31.4)$ & $10(15.6)$ & 0.06 \\
\hline
\end{tabular}


Table 2. Univariate analysis for disease-specific survival and disease-free survival of the OSCC patients.

\begin{tabular}{|c|c|c|c|c|}
\hline \multirow[b]{2}{*}{ Parameter } & \multicolumn{2}{|c|}{ Disease-specific survival } & \multicolumn{2}{|c|}{ Disease-free survival } \\
\hline & $\%$ in 5 years & $\mathrm{HR}(95 \% \mathrm{Cl}) / \mathrm{p}$ value & $\%$ in 5 years & $\mathrm{HR}(95 \% \mathrm{Cl}) / \mathrm{p}$ value \\
\hline \multicolumn{5}{|l|}{ Age } \\
\hline$<57$ years & 57.1 & Reference & 62.4 & Reference \\
\hline$\geq 57$ years & 34.0 & $1.84(1.07-3.16) / 0.02$ & 57.8 & $1.22(0.62-2.39) / 0.55$ \\
\hline \multicolumn{5}{|l|}{ Gender } \\
\hline Male & 45.3 & Reference & 63.5 & Reference \\
\hline Female & 42.9 & $1.16(0.55-2.48) / 0.66$ & 46.2 & $1.59(0.64-3.97) / 0.23$ \\
\hline \multicolumn{5}{|l|}{ Smoking habit } \\
\hline No & 51.8 & Reference & 68.3 & Reference \\
\hline Yes & 46.9 & $1.42(0.60-3.38) / 0.35$ & 47.1 & $1.99(0.63-6.23) / 0.12$ \\
\hline \multicolumn{5}{|l|}{ Drinking habit } \\
\hline No & 51.8 & Reference & 82.8 & Reference \\
\hline Yes & 46.9 & $1.60(0.82-3.12) / 0.20$ & 59.8 & $1.67(0.68-4.06) / 0.29$ \\
\hline \multicolumn{5}{|l|}{ Clinical stage } \\
\hline Early (I + II) & 54.2 & Reference & 62.2 & Reference \\
\hline Advanced (III + IV) & 34.7 & $1.92(1.11-3.31) / 0.02$ & 56.3 & $1.13(0.57-2.24) / 0.72$ \\
\hline \multicolumn{5}{|l|}{ Tumor site } \\
\hline Tongue & 54.0 & Reference & 63.2 & Reference \\
\hline Others & 34.7 & $0.87(0.51-1.50) / 0.63$ & 58.4 & $1.05(0.53-2.07) / 0.87$ \\
\hline \multicolumn{5}{|l|}{ Treatment } \\
\hline Surgery & 53.3 & Reference & 60.1 & Reference \\
\hline Surgery + Radiotherapy & 50.0 & $1.22(0.69-2.15) / 0.51$ & 59.2 & $1.13(0.55-2.31) / 0.72$ \\
\hline Surgery + Radiotherapy + Chemotherapy & 35.4 & $1.34(0.55-3.27) / 0.43$ & 64.3 & $0.87(0.26-2.89) / 0.83$ \\
\hline \multicolumn{5}{|l|}{ Histological grade } \\
\hline Well-differentiated + Moderately-differentiated & 45.3 & Reference & 74.1 & Reference \\
\hline Poorly-differentiated & 34.1 & $1.80(0.66-4.93) / 0.13$ & 59.5 & $1.48(0.44-4.95) / 0.58$ \\
\hline \multicolumn{5}{|l|}{ Margin status } \\
\hline$\geq 5 \mathrm{~mm}$ & 44.0 & Reference & 62.1 & Reference \\
\hline$<5 \mathrm{~mm}$ & 50.0 & $0.92(0.12-7.21) / 0.94$ & 100 & NA \\
\hline \multicolumn{5}{|l|}{ STC2 } \\
\hline Low & 63.4 & Reference & 74.5 & Reference \\
\hline
\end{tabular}


Table 3. Cox multivariate analysis for the risk of death and recurrence.

\begin{tabular}{lllll}
\hline Parameter & \multicolumn{2}{l}{ Disease-specific survival } & \multicolumn{2}{l}{ Disease-free survival } \\
& $\mathrm{HR}(95 \% \mathrm{Cl})$ & $\mathrm{p}$ value & $\mathrm{HR}(95 \% \mathrm{Cl})$ & $\mathrm{p}$ value \\
\hline Age & & & & \\
$<57$ years & Reference & & & \\
$\geq 57$ years & $1,95(1.12-3.38)$ & 0.01 & & \\
STC2 & & & & \\
Low & Reference & & Reference & \\
High & $2.67(1.37-5.21)$ & 0.001 & $2.80(1.07-5.71)$ & 0.03 \\
\hline
\end{tabular}




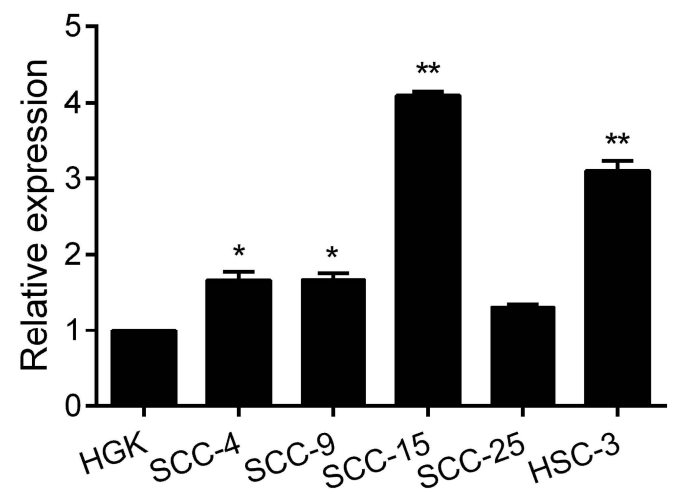




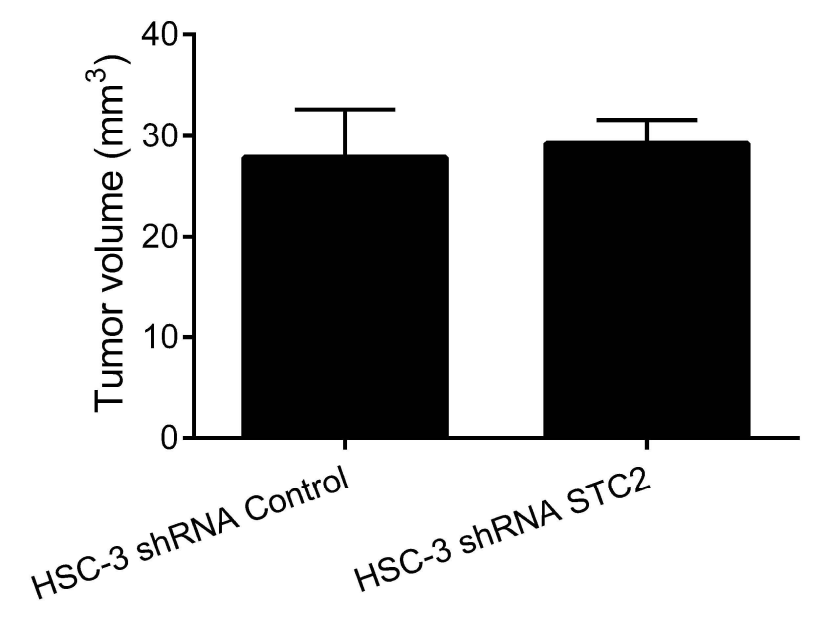



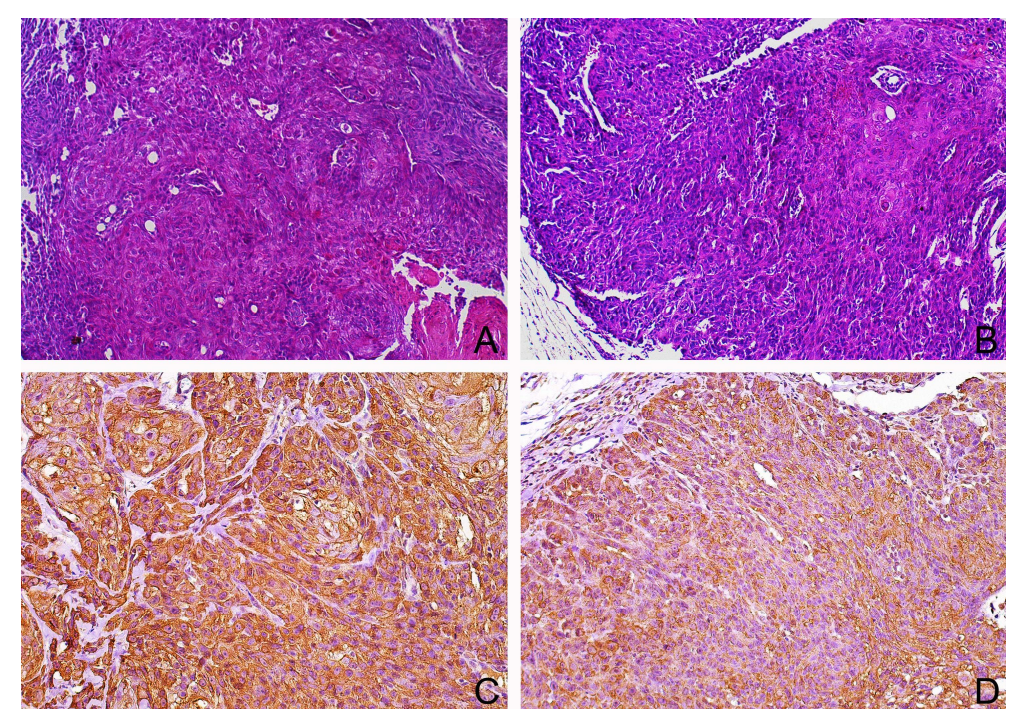
Supplementary Table 1. Description of primers used in the qPCR.

\begin{tabular}{|c|c|}
\hline Primers & Sequence $\left(5^{\prime} \rightarrow 3^{\prime}\right)$ \\
\hline \multirow[t]{2}{*}{ STC2 } & Forward: GCATGTCACACGCAGGATTCT \\
\hline & Reverse: TGTCCGTTCCGCGAACA3 \\
\hline \multirow[t]{2}{*}{ E-cadherin } & Forward: ACAGCCCCGCCTTATGATT3 \\
\hline & Reverse: TCGGAACCGCTTCCTTCA \\
\hline \multirow[t]{2}{*}{ Vimentin } & Forward: GGCTCGTCACCTTCGTGAAT \\
\hline & Reverse: TCAATGTCAAGGGCCATCTTAA \\
\hline \multirow[t]{2}{*}{ Snail1 } & Forward: GCGTGTGCTCGGACCTTCT \\
\hline & Reverse: ATCCTGAGCAGCCGGACTCT \\
\hline \multirow[t]{2}{*}{ Snail2 } & Forward: GGAGCATACAGCCCCATCA \\
\hline & Reverse: TGGTAGCTGGGCGTGGAA \\
\hline \multirow[t]{2}{*}{ Zeb1 } & Forward: GCTTTCCCATTCTGGCTCCTA \\
\hline & Reverse: TCTTGGTCGCCCATTCACA \\
\hline \multirow[t]{2}{*}{ Zeb2 } & Forward: AAGATAGGTGGCGCGTGTTT \\
\hline & Reverse: ACTGACGTGTTACGCCTCTTCTAA \\
\hline \multirow[t]{2}{*}{ Twist } & Forward: GCGCTGCGGAAGATCATC3 \\
\hline & Reverse: GCTTGAGGGTCTGAATCTTGCT \\
\hline \multirow[t]{2}{*}{ MMP-2 } & Forward: GTTCATTTGGCGGACTGT \\
\hline & Reverse: AGGGTGCTGGCTGAGTAG \\
\hline \multirow[t]{2}{*}{ MMP-9 } & Forward: CTTTGGACACGCACGAC \\
\hline & Reverse: CCACCTGGTTCAACTCACT \\
\hline \multirow[t]{2}{*}{ PPIA } & Forward: GCTTTGGGTCCAGGAATGG \\
\hline & Reverse: GTTGTCCACAGTCAGCAATGGT \\
\hline
\end{tabular}

